\title{
Correction to: Dihydroxanthyletin-type coumarins from Angelica decursiva that inhibits the formation of advanced glycation end products and human recombinant aldose reductase
}

\author{
Md Yousof Ali ${ }^{1} \cdot$ Hyun Ah Jung ${ }^{2} \cdot$ Susoma Jannat $^{1} \cdot$ Jae Sue Choi $^{1}$
}

Published online: 12 January 2019

(c) The Pharmaceutical Society of Korea 2019

Correction to: Arch. Pharm. Res. (2018) 41:196-207

https://doi.org/10.1007/s12272-017-0999-6

The author would like to include conflict of interest statement of the online published article. The correct conflict of interest statement should read as:

\section{Conflict of interest}

The authors declare no conflict of interest.

The original article can be found online at https://doi.org/10.1007/s12272-017-0999-6.

\footnotetext{
Hyun Ah Jung jungha@jbnu.ac.kr

$\triangle$ Jae Sue Choi choijs@pknu.ac.kr

1 Department of Food and Life Science, Pukyong National University, Busan 48513, Republic of Korea

2 Department of Food Science and Human Nutrition, Chonbuk National University, Jeonju 54896, Republic of Korea
} 